\title{
Clinical trials: innovation, progress and controversy
}

This article was published in the following Dove Press journal:

Open Access Journal of Clinical Trials

I August 20| |

Number of times this article has been viewed

\section{Greg S Martin}

Department of Pulmonary, Allergy and Critical Care, Emory University, Atlanta, Georgia, USA
Correspondence: Greg S Martin

Department of Pulmonary, Allergy and Critical Care, Emory University, 49 Jesse Hill Jr Drive SE, Atlanta, GA 30303, USA Tel +l 4046160148

Fax +I 4046165008

Email greg.martin@emory.edu
The Open Access Journal of Clinical Trials began in 2009 with the goal of being an authoritative, open access source for international, peer-reviewed publications in the field of human research and clinical trials. Since then, the Open Access Journal of Clinical Trials has published approximately 30 high-quality articles on original research, innovative reviews, and critical commentaries. These articles have spanned many aspects of clinical trials wonderfully, including trial design and management; legal, ethical and regulatory issues of clinical trials; subject participation and retention in clinical trials; and data collection and data management. The breadth of subjects covered is remarkable, with articles discussing study subject enrollment, engagement, and retention; $;^{1-4}$ the effects of participant heterogeneity on intermediate phase clinical trials $;{ }^{5}$ important methodological concerns with complementary and alternative medications; ${ }^{6}$ modern issues with clinical-trial data management; ${ }^{7}$ and state-of-the-art reviews of clinical importance such as pharmacological drug toxicity ${ }^{8}$ and biomarkers in cardiovascular diseases. ${ }^{9}$ To complement these contemporary commentaries and reviews, the Open Access Journal of Clinical Trials has published original research in a number of different fields in medicine, biostatistics, and epidemiology. Perhaps even more remarkable than the breadth of subjects is the international representation of authors, who hail from Europe, Africa, Australasia, and North America. As a testament to the diversity and value presented by the Open Access Journal of Clinical Trials, I encourage you to browse the recent editions and pick one of the articles that piques your interest.

Authors of manuscripts submitted to the Open Access Journal of Clinical Trials have enjoyed rapid review and publication, with the first set of reviewer comments currently being returned in an average of only 10 days. This is remarkable in an era of burgeoning clinical research and growth in the biomedical sciences, and authors have found that our peer reviewers' comments are both focused and critically useful for improving their manuscript. The open access format and online publication process have enabled the reviewers and editorial staff to work more efficiently despite the international nature of the submissions and the reviewers. In addition, the open access journal format and electronic nature of the journal makes published manuscripts freely available to anyone in the world. Another benefit of the manuscript system used by the Open Access Journal of Clinical Trials is the opportunity for authors to become "Favored Authors" to permit fast-tracking and personal coordination of submitted 
manuscripts, as well as a discount on publication processing fees (http://www.dovepress.com/fav_author.php).

With such an outstanding start to a new journal, the future of Open Access Journal of Clinical Trials is bright indeed! The field of clinical and translational research, particularly that of clinical trials, continues to grow exponentially. If news reported through Google Trends regarding clinical research is any indication, the growth of both clinical research and clinical trials outpaces research news reports on any other subjects. ${ }^{10}$ Future issues of the Open Access Journal of Clinical Trials will spotlight areas of particular interest or innovation in the field of clinical trials. There is tremendous interest in areas of controversy, such as the review of clinical trials by multiple ethical boards (or institutional review boards) and the related impact on trial conduct and efficiency, ${ }^{11}$ as well as methods to maximize benefits to trial participants in areas of uncertainty and concerns about equipoise. ${ }^{12}$ The recent development of virtual clinical trials has the potential to revolutionize the way in which clinical trials are conducted, ${ }^{13}$ and proposals for collaborative trials with unified protocols and direct comparisons could equally transform the process for drug and device development and approval in countries throughout the world. ${ }^{14}$ Novel approaches in clinical trial design and adaptive randomization, purporting to improve patient safety and trial efficiency while minimizing ethical concerns about exposure to inferior treatments, are inevitable parts of future clinical trial reports. New regulations intended to streamline regulatory procedures for clinical trials while enhancing the protection of human subjects are of equally high interest. ${ }^{15}$ Perhaps most important for patients and our society, patient-centered outcomes research, as promulgated in US health care reform, ${ }^{16}$ is a new twist on outcomes research and comparative effectiveness research that will include more community engagement and knowledge translation to ensure that clinical trial discoveries really reach the people that need them. ${ }^{17}$

For those of you interested in the Open Access Journal of Clinical Trials and the field of clinical trials, please do not hesitate to contact me. I am eager for any comments about the papers we publish, whether they are positive, negative, or simply provide further information.

\section{References}

1. Burgess LJ, Sulzer NU. The role of print advertising in clinical trial recruitment: lessons from a South African site. Open Access J Clin Trials. 2010;2:83-87.

2. Frew PM, Mulligan MJ, Hou S, Chan K, del Rio C. Time will tell: community acceptability of HIV vaccine research before and after the "Step Study" vaccine discontinuation. Open Access J Clin Trials. 2010;2:149-156.

3. Olem D, Sharp KM, Johnson MO. Challenges with engaging participants in behavioral intervention research trials. Open Access J Clin Trials. 2009;1:17-21.

4. Burgess LM, Sulzer NU. Retrospective analysis of a South African cardiovascular trial site's patient retention rates. Open Access J Clin Trials. 2010;2:163-166.

5. Barnes CN, Rai SN. The effects of heterogeneity on Simon Phase II clinical trial design operating characteristics. Open Access J Clin Trials. 2010;2:107-114.

6. Bansal D, Hota D, Chakrabarti A. Research methodological issues in evaluating herbal interventions. Open Access J Clin Trials. 2010;2:15-21.

7. Lu Z, Su J. Clinical data management: current status, challenges, and future directions from industry perspectives. Open Access J Clin Trials. 2010;2:93-105.

8. Lockwood A, Patka P, Rabinovich M, Wyatt K, Abraham P. Sodium nitroprusside-associated cyanide toxicity in adult patients - fact or fiction? A critical review of the evidence and clinical relevance. Open Access J Clin Trials. 2010;2:133-148.

9. Benatar JR. Trans fatty acids and coronary artery disease. Open Access J Clin Trials. 2010;2:9-13.

10. Google Trends. Clinical research [web search engine search on the Internet]. Mountain View, CA: Google; 2008. Available from: http:// www.google.com/trends? $q=$ clinical + research $\&$ ctab $=0 \&$ geo $=$ all $\&$ date $=$ all\&sort $=0$. Accessed July 19, 2011.

11. Menikoff J. The paradoxical problem with multiple-IRB review. NEngl J Med. 2010;363(17):1591-1593.

12. Miller FG, Joffe S. Equipoise and the dilemma of randomized clinical trials. N Engl J Med. 2011;364(5):476-480.

13. Roehr B. Pfizer launches virtual clinical trial. BMJ. 2011;342:d3722.

14. Moss AJ, Francis CW, Ryan D. Collaborative clinical trials. $N$ Engl J Med. 2011;364(9):789-791.

15. Sherman RB, Woodcock J, Norden J, Grandinetti C, Temple RJ. New FDA regulation to improve safety reporting in clinical trials. $N$ Engl $J$ Med. 2011;365(1):3-5.

16. Patient-Centered Outcomes Research Institute [homepage on the Internet]. Washington: Patient-Centered Outcomes Research Institute; 2011 [updated July 2011]. Available at: http://www.pcori.org. Accessed July 14, 2011.

17. Ware JH, Hamel MB. Pragmatic trials - guides to better patient care? N Engl J Med. 2011;364(18):1685-1687.
Open Access Journal of Clinical Trials

\section{Publish your work in this journal}

The Open Access Journal of Clinical Trials is an international, peerreviewed, open access journal publishing original research, reports, editorials, reviews and commentaries on all aspects of clinical trial design, management, legal, ethical and regulatory issues, case record form design, data collection, quality assurance and data auditing

\section{Dovepress}

methodologies. The manuscript management system is completely online and includes a very quick and fair peer-review system, which is all easy to use. Visit http://www.dovepress.com/testimonials.php to read real quotes from published authors. 